\title{
SMART CITIES NO ATUAL ESTÁGIO DA CIDADE-EMPRESA: PERSPECTIVAS TECNOPOLÍTICAS PARA O DIREITO À CIDADE
}

\author{
Jorge Alberto de Macedo Acosta Júnior* \\ Norberto Milton Paiva Knebel**
}

RESUMO: O objetivo deste foi trazer perspectivas tecnopolíticas para a repolitização da cidade no contexto informacional da cidade-empresa. O método é da revisão bibliográfica numa abordagem dialética. A teoria aponta para a necessidade de reapropriação dos meios tecnológicos informacionais pelo cidadão, a expropriação da tecnologia do planejamento estratégico para a sociedade. Para o direito à cidade essa prática é fundamental como núcleo da dupla revolução que o fundamenta - da vida cotidiana e da gestão.

PALAVRAS-CHAVE: Direito à Cidade; Cidades Inteligentes; Cidade-Empresa; Tecnopolítica; Cidadania Digital.

\section{SMART CITIES IN THE CURRENT CITY-BUSINESS: TECNOPOLITICAL PERSPECTIVES FOR THE RIGHT TO THE CITY}

\begin{abstract}
The objective of this was to bring tecnopolitical perspectives for the repolitization of the city in the informational context of the city-business. The method is from the bibliographic review in a dialectical approach. The theory points to the need to reappropriate the technological information media by the citizen, the expropriation of the technology of strategic planning for society. For the right to the city this practice is fundamental as the nucleus of the double revolution that underlies it - everyday life and management.
\end{abstract}

KEYWORDS: Right to the City; Smart Cities; City-Business; Technopolitics; Digital Citizenship.

\footnotetext{
* Mestre em Direito pela Universidade La Salle/ Canoas-RS. Pesquisador no grupo de pesquisas Teorias Sociais do Direito na mesma instituição. Contato: Jorge.acosta.jr88@gmail.com

${ }^{* *}$ Mestre em Direito pela Universidade La Salle/ Canoas-RS. Pesquisador no grupo de pesquisas Teorias Sociais do Direito na mesma instituição. Contato: Norberto.knebel@gmail.com
} 


\section{INTRODUÇÃO}

O atual estágio de desenvolvimento do meio-técnico-científico-informacional compreende a formação das cidades inteligentes, como forma de gestão e planejamento urbano sustentado no tratamento da informação. Todavia, detecta-se uma apropriação dos mecanismos da tecnologia da informação pela gestão corporativa e capitalista da cidade, contribuindo para a era informacional da cidade-empresa - figurando como nova arma em prol da despolitização do espaço urbano. Dentro dessa realidade, é preciso detectar quais serão as formas possíveis de politizar a comunicação informacional que molda as práticas urbanas, por isso o objetivo deste é justamente apontar os aspectos de conexão entre a política das redes informacionais e a rua.

Esse tema é atual e justifica este artigo, pois as cidades inteligentes são fenômenos internacionais - vistos como solução de problemas habituais por alguns e por outros visto como o agravamento da gestão capitalista das cidades. Casos de cidades com desenvolvimento econômico associados à técnicas de planejamento urbano "smart" têm sido propagandeados como modelos para cidades brasileiras, porém, sem confrontar as contradições que tornaram ineficientes outras plataformas no passado.

O problema da despolitização da cidade, que concerne a questão deste artigo - da apropriação capitalista dos meios informacionais -, é o tema central do que Lefebvre entende por Direito à Cidade, por isso os aspectos de uma possível reapropriação da política nas redes deve ser também da política das ruas. Acerca do marco teórico lefebvriano, será adotada a coerência com o conceito de Direito à Cidade rígido ao tratamento de uma crítica da economia política e atrelado fundamentalmente às lutas sociais, é, portanto, vinculado ao termo de forma crítica aos valores jurídicos e políticos que a ele têm sido vulgarmente designados ${ }^{1}$.

Para pensar respostas a esses processos intensamente informacionais, ao nível da instantaneidade e da profusão de dados que constitui o que é chamado de "big data", apresentam-se questões de fundo dignos da ciência política, que aqui, ao fim de pensar o espaço informacional chega-se ao conceito de tecnopolítica, que sugere preocupações pertinentes ao contexto, de forma equivalente aquelas do espaço urbano - principalmente ao enfrentar a gestão das cidades sob a ótica da tecnologia da informação. Assim, adotando perspectiva que

\footnotetext{
${ }^{1}$ Sobre essa crítica ao uso esvaziado do termo "direito à cidade", ver em BONFIGLI e KNEBEL (2017) como as práticas jurídicas são alheias à natureza de dúplice revolução (da vida cotidiana e da gestão) inerente ao Direito à Cidade, também como CARLOS (2017) salienta o caráter utópico do termo, que é uma forma de pensar uma nova cidade e TAVOLARI (2016) que aponta a trajetória do conceito, de como tem sido enfraquecido do ponto de vista teórico, mas ainda se mantém como salvaguarda das lutas sociais pela cidade.
} 
contempla a tecnopolítica como forma de organização de resistência ou revoluções, para além de conceitos como "ciberativismo" e "hacktivismo" - que descrevem grupos e restringem-se a momentos.

Dessa forma, constitui-se um problema de pesquisa teórico que busca resposta na política de como tratar as cidades inteligentes do ponto de vista político - reconhecida uma tendência de despolitização na cidade capitalista e uma necessidade de repolitização pelo que se entende como direito à cidade. Para isso, este artigo busca desenvolver uma reflexão dialética (como modo de abordagem) entre o desenvolvimento histórico e espacial da cidade com um par sociológico e da ciência política. Dado ao caráter teórico, a técnica de pesquisa utilizada é da revisão bibliográfica, justamente por buscar perspectivas que se correspondam ou se oponham - dos traços que sustentam as cidades inteligentes capitalistas aos eixos da organização tecnopolítica revolucionária.

\section{SMART CITIES NO CONTEXTO DA CIDADE-EMPRESA}

As cidades inteligentes, conhecidas pelo termo "smart cities", são a concepção contemporânea de espaços urbanos ordenados pela inédita expansão do meio informacional pela via digital, tendo em vista o paradigma dos ICTs (information and communications technology). Se dá pelo ponto de vista política, pois é um apelo de governança do "meio técnico-científico-informacional” - como já apontava Milton Santos ao identificar os avanços das formas tecnológicas e informáticas de produção do espaço urbano.Esse é o atual estágio do desenvolvimento de um processo - da relação entre a sociedade e a natureza, na plena substituição de um meio natural para um meio instrumentalizado pela sociedade (adquirindo forma inerente a sua lógica de produção).

Dentre essas fases SANTOS (2006) destaca três grandes momentos: (I) meio natural: na qual havia relação primitiva com um ambiente natural; (II) meio técnico: que compreende o período de mecanização da sociedade, porém, circunscrito às regiões que se desenvolviam na forma industrial; e (III) o meio técnico-científico-informacional: que corresponde ao estágio do espaço em que há uma união entre ciência e técnica sob a égide de um mercado global, por isso o autor aponta esse meio como "a cara geográfica da globalização” (p. 160).

Dessa forma, os objetos que cada vez mais são inteirados com uma técnica, se subordinam às lógicas globais - que conformam tanto os investimentos em capital fixo e constante, com a necessidade de movimento, compreendendo a lógica de fluxos que expressa 
as novas relações pautadas pela financeirização. Nessa aproximação da geografia e da economia que surge as análises das chamadas "redes", como CASTELLS (2005, p. 119) chama a nova economia informacional, global e em redes:

É informacional porque a produtividade e competividade de unidades ou agentes nessa economia (sejam empresas, regiões ou nações) dependem basicamente de sua capacidade de gerar, processar e aplicar de forma eficiente a informação baseada nos conhecimentos. É global porque as principais atividades produtivas, o consumo e a circulação, assim como seus componentes (capital, trabalho, matéria-prima, administração, informação, tecnologia e mercados) estão organizados em escala global, diretamente ou mediante uma rede de conexões de agentes econômicos. É rede porque, nas novas condições históricas, a produtividade é gerada, e a concorrência é feita em uma rede global de interação entre redes empresariais.

Entretanto, especificamente, as "smart cities" refletem esse fenômeno na configuração do espaço urbano e na mobilidade - que se refletem de maneira territorial, ao transformar o complexo urbano em um organismo-rede inédito, que do ponto de vista da comunicação refletem uma nova relação com o tempo e o espaço. Assim, a civilidade (ou socialização) da urbanidade é alterada pela formação de territórios informacionais, regulados pelos meios de comunicação massivos e imediatos (LEMOS, 2007).

Portanto, há uma caracterização social desse atual estágio das cidades capitalistas, embora sejam chamadas pelo planejamento estratégico de "smart cities", são sinônimos da identificação do mesmo processo de reestruturação territorial os termos "cibercidade" ou “cibercidadania”, por exemplo, em que PIRES (2003) aponta para as cidades que privilegiam as relações econômicas e culturais de cunho informacional em favor de uma acumulação pelo advento de cada vez mais atuais serviços digitais.

Sob o olhar da cultura, a ascensão da cidade informacional é enxergada dentro do contexto da sociedade em rede, como prolongamento dos processos de urbanização, em um estágio que representa o advento das interações entre a cidade física e a cidade digital. Porém, é preciso afirmar que não é o fim da forma urbana, mas sim a afirmação da mesma - apoiada pela cibercultura, e até mesmo por essas trocas entre informação digital e cidade de concreto que pode ser chamada de "telemediação" - que autores chamam essa nova cidade de "cidadeciborgue" (LEMOS, 2004).

Do ponto de vista do planejamento estratégico e seu desejo de construir cidades inteligentes - ou "tomar as rédeas" da cidade informacional -, é possível elencar quatro grandes paradigmas tecnológicos para esse contexto urbano, seja pela tendência contemporânea de 
produção do espaço mercadoria - na projeção da expansão dos investimentos imobiliários privados - e dos projetos ao nível de planejamento urbano e regional:

(I) Big Data: é a formação de técnica e método para armazenamento e interpretação de conjuntos de dados gigantescos, tendo como característica o cuidado com o volume, a variedade, a velocidade e a veracidade ${ }^{2}$, justamente pela quantidade inédita tornou-se um paradigma. $(\mathrm{CHENG}, 2015)^{3}$

(II) Data-Driven Urbanism: sugere uma gestão da cidade por via dos dados gerados por ela e sobre ela. Embora não seja novidade que os dados tenham influência no planejamento urbano, a questão atual é que os dados mais que informam a governança, mas a dirigem, justamente pela capacidade da administração de grande volumes de dados gerarem redes de informação, criando, em teoria uma cidade governada do ponto de vista pragmático e eficiente baseado em evidências - que acabam por sucumbir aos interesses seletivos, sejam normativos ou/ e políticos ${ }^{4}$. (III) Tecnologia de Informação Sensível ao Contexto: gestão e criação de dados digitais que corrobora a entrada e saída de dados de acordo com o contexto do usuário, do ambiente e do tempo, agindo de forma ativa a interpretar os dados, que não podem mais ser considerados simples, mas sim geridos e categorizados conforme o contexto - principalmente na relação entre os usuários que se transformam na relação entre objetos autônomos (a chamada "internet das coisas"). ${ }^{5}$ (IV) Gestão atuarial/ algorítmica A partir e ao mesmo tempo da concepção e da gestão dos dados são construídos algoritmos que fundamentam as políticas urbanas - seja na gestão pública ou na privada (mas principalmente na segunda) - sendo permanentemente reformados ao passo do implemento das informações (que segundo falado acima, são mais que dados, mas sim evidências). Assim, surgem serviços algorítmicos sustentados por cálculos baseados na restrição ao risco.

A partir disso se discute como a cidade baseada em dados tecnológicos irá contemplar paradigmas éticos em relação a gestão dos dados. É nesse ponto que se identificam desafios a implementação da tecnologia na gestão das cidades, ao passo que danos definitivos possam ser

\footnotetext{
${ }^{2}$ Ver: CHENG, 2015.

${ }^{3}$ Sobre o volume de dados ser um paradigma, ver: KITCHIN, 2014.

${ }^{4}$ Ver: KITCHIN, 2015.

${ }^{5}$ Ver: DA SILVA, 2016.
} 

identificados tarde demais. EM QUE SE BASEIA A GESTÃO DOS DADOS PROMOVIDOS PELA CIDADE? Tanto aqueles que os sistemas autônomos produzem sobre nossas vidas como aqueles que nós mesmos produzimos aos aplicativos (ou sistemas em geral).

Para além do fato sociológico que é a afirmação das cidades informacionais, é no planejamento estratégico, ou a lógica chamada de "cidade-empresa", que ocorre a apreensão capitalista desse fenômeno, é na gestão da cidade que é estruturalmente moldada para os mecanismos de acumulação flexível. Essa relação entre a gestão e a lógica corporativa que forma a metáfora "cidade-empresa" serve justamente para expressar quais são os principais agentes e estratégias do desenvolvimento urbano - do empreendedorismo competitivo e tecnocrático. (VAINER, 2011)

Nesse contexto a cidade está inserida numa lógica de inserção competitiva das cidades no mercado, pois traz uma significativa mudança na linguagem do planejamento ou da gestão, pois o espaço de representação é difundido pelo "city marketing" e das manipulações simbólicas dos discursos em nome da eficiência tecnocrática, muitas vezes chamada de integração competitiva. O lucro e o desenvolvimento são tratados como interesse de todos de forma instrumental no discurso dominante, mascarando a luta estrutural das cidades - do formal ao informal, das cidades e não-cidades. (SANCHEZ, 2003)

Porém, embora inspirada pela competitividade empresarial, essa cidade nada tem de conflituosa, pois nega radicalmente a cidade como espaço político. O consenso é um princípio e um fim do planejamento estratégico, pois se baseia na participação direta dos agentes econômicos - ou o que VAINER (2000b) chama de ditadura gerencial ou ditadura direta da burguesia -, escondendo conflitos sociais e de classe em nome de uma ideia de consentimento sustentado pelo aval da população e da celebração das valorizações econômicas.

Essa gestão da cidade é uma evolução daquela cidade corporativa, da cidade empresa baseada na eficiência pretendida na administração privada das corporações. Dessa forma, tal qual nas empresas em que o empregado é chamado de "colaborador", na cidade-empresa em sua forma "smart" o cidadão nada mais é que um usuário/ consumidor - além dos tributos, contribui com os dados para a gestão, sem interferir nos objetivos dela.

O planejamento estratégico das cidades está fundado como uma negação obrigatória da cidadania, seja como consumidor de mercadorias ou acionista de empresa, está condenado a extinção do espaço público. É o que VAINER(200b) aponta como o surgimento da "city" em detrimento da pólis - espaço político de igualdade, encontro e debate entre cidadãos. Esse cidadão-consumidor além dessa restrição política, serve ao mercado somente em sua 
capacidade econômica de consumir luxos - assim, restritos a quem não pode, restando a elas somente o vazio político e o evitamento.

Essa analogia com o consumidor se dá justamente pelo aprofundamento da relação do cidadão com a cidade interpelada pela forma mercadoria, da mesma forma que o produto do seu trabalho e dos bens de consumo da sociedade do espetáculo serem frutos de profunda alienação, os serviços básicos da cidade também são vinculados a esse mesmo processo. A mobilidade urbana, por exemplo, mais que o transporte e o acesso à vida urbana, passa a ser um produtor de dados - sendo essa a unidade mais importante dessa forma mercadoria.

Dessa maneira, a gestão urbana é dirigida muito mais pelos gestores dos algoritmos de aplicativos ou redes sociais que pela participação dos cidadãos (LEAL, 2012), que outrora eram cogitados como participantes na gestão da política urbana mas agora produzem dados praticamente gratuitos em nome da gestão por outros. Enquanto se esperava que a expansão dos dados e as novas possibilidades de tratamento fossem melhor informar a produção de um planejamento urbano que contemplasse mais atores, ocorreu o contrário, pois os dados já nascem tratados por aqueles que os controlam.

Como já alertava Carlos VAINER (2000a), o planejamento urbano liberal tem tido justamente essa natureza de forjar consensos e ocultar ou deslegitimar dissensos e conflitos, por isso, na atualidade, trata a expropriação dos dados e da vida urbana como um consenso em nome da eficiência, pautada na construção de identidades e alianças falaciosas. Corroborando ainda com outro alerta, por Milton SANTOS (2000): a expansão contínua da cidade do pensamento único pela globalização.

Há, portanto, uma necessidade de que a sociedade impeça os processos de domesticação da tecnologia pelos agentes estratégicos do capitalismo que capturam as funções e as estruturas intimamente ligadas ao interesse público (MACHADO, 2018), compreendendo como o avanço das tecnologias pode permitir algo alheio ao desenvolvimento dos serviços públicos, mas também a passagem de agendas contrárias ao bem-estar da sociedade (WEISS; BERNARDES; CONSONI, 2015)

É necessário atenção (e luta) ainda mais especial na realidade atual das cidades, esses processos podem ser vistos de maneira material no dia-a-dia da produção da cidade. Como afirma Ermínia Maricato, para que não se esqueça de como estruturas da economia política são expostas na cidade: “É a questão urbana, estúpido!”. ${ }^{6}$ A resistência ao movimentos capitalistas

\footnotetext{
${ }^{6}$ Ver: MARICATO, 2013.
} 
de apropriação podem significar a formação de novas utopias, ou metatopias para uma cidade governada pelo comum (NEVES, 2018) em caso de reapropriação.

Essa perspectiva de retomado do poder sobre a tecnologia de informação está no campo dos novos direitos urbanos, conforme ANJOS (2017), que constitui a ocupação do espaço político da cidade na produção de novas formas paralelas de institucionalidades democráticas, formas adequadas e transformadoras de participação, entre elas está a via tecnopolítica.

\section{REAPROPRIAÇÃO DAS REDES PELA ORGANIZAÇÃO TECNOPOLÍTICA}

O desenvolvimento tecnológico e científico sem paralelo testemunhado pelo humano na sociedade contemporânea incorpora-se inexoravelmente às mudanças organizacionais de todo o conjunto social. A descrição deste fenômeno, ou seja, a observação desta interferência resta imbricada por um conjunto de reproduções que ocultam a maneira material cotidiana da produção da cidade. Essa camada de opacidade das relações sociais relativas à reprodução técnico-científico-informacional chamaremos de tecnopolítica, uma dinâmica social que se apresenta na transição de uma sociedade centrada no paradigma informacional para um paradigma do conhecimento.

A percepção da cidade encontra-se desorientada, acompanhamos seu crescimento caótico com desesperança na inversão do processo de exclusão inerente das bases acumulatórias do nível global. A transformação do cidadão em consumidor não é apenas um processo decorrente da expansão da tecnologia, trata-se da relação primordial que a estrutura capitalista, em outras palavras, o sujeito autônomo da economia política tem com a manipulação da informação. Nesta linha de pensamento, a importância da observação ocorre não nas informações em si, mas em como as informações são (auto)organizadas, em suma, como se transformam em conhecimento.

O pensamento do sociólogo espanhol Manuel Castells (2005) baseia-se na observação das inovações tecnológicas informacionais como a microeletrônica, computação (software $e$ hardware), a telecomunicação, radiodifusão, a optoeletrônica, a engenharia genética e seus desenvolvimentos e aplicações próprias, difundiram-se rapidamente no globo terrestre de modo a interligar a população mundial, privilegiando territórios dominantes e reafirmando determinados grupos sociais. 
Para que as elites globais possam se estabelecer e usufruir de sua posição há um processo histórico de incremento e estabilização de forças sociais, ou seja, de uma relação de poder determinada e, também, determinante. Castells (2009), em seu livro Comunicación y poder, indica o poder como processo fundamental da sociedade, eis que este define as instituições e os valores. Em outras palavras, o poder é a capacidade relacional que determinado ator social tem de influenciar de forma assimétrica nas decisões de outros atores sociais, de modo que se favoreça à vontade, valores e interesses do ator que tem poder.

Além desta definição de poder, Castells (2009) avança, delimitando que o exercício do poder se dá pela coação e/ou mediante a construção de significados, na construção de discursos em que o atores sociais guiam suas ações. Existe então uma estruturação da dominação nas relações sociais que reside nas instituições, estas últimas exercendo dominação em seus sujeitos. Dada a amplitude desta conceituação, apresenta-se a necessidade de se observar as ponderações de Castells em cada conceito utilizado: ator social, descreve todo o sujeito da ação, isto é, os sujeitos individuais ou coletivos, abarcando nesta conceituação as organizações, as instituições e as redes; a capacidade relacional, significa que o poder não é uma condição, e sim, uma relação, mais especificamente, entre os sujeitos que empoderados e aqueles submetidos nesta relação, em determinada contexto; A assimetria da relação de poder consiste, além da superioridade relacional de um ator e outro, na condição de que a relação será sempre recíproca, ou seja, há sempre a possibilidade de resistência e, por conseguinte, a troca institucional ou estrutural, dependendo da abrangência da modificação do status quo. Nesta mesma linha sobre a interrelação, o sociólogo acrescenta que a inexistência de intercambio nas relações de poder acaba por constituir relações não sociais, em suas palavras, "la pura imposición por la fuerza no es una relación de social, ya que lleva a la obliteración del actor social dominado, de forma que la relación desaparece con la extinción de una de sus condiciones" (CASTELLS, 2009, p. 34).

O poder necessita da legitimação para que não seja necessária a constante utilização da violência para sua manutenção, assim, utiliza-se da criação de significados em nome destes determinados interesses e valores, sustentando a legitimação, por sua vez agindo no consentimento compartilhado dos atores sociais. Interliga-se, nesta linha, a noção de que a crença na democracia representativa faz com que os atores sociais desenvolvem ações que possibilitem o exercício do poder, isto é, o credo de que o Estado, através da democracia, fará a entrega do poder de forma legítima, viabilizando sua capacidade de coação, bem como, seus 
recursos comunicativos, os quais facilitam a produção de significados para estabilizar suas relações de poder.

Embora a crença, a sociedade não representa o consenso, as estruturas sociais integram-se de forma contraditória, eis que os conflitos entre os atores sociais são apaziguados por contratos não estabelecidos ou armistícios temporários, os quais, por sua vez, são aproveitados pelos detentores do poder para o estabelecimento de instituições de dominação. A estruturação do poder ocorre de maneira complexa em diferentes contextos da prática social, assim, afirma Castells que,

\footnotetext{
el poder no se localiza en una esfera o institución social concreta, sino que está repartido en todo el ámbito de la acción humana. Sin embargo, hay manifestaciones concentradas de relaciones de poder en ciertas formas sociales que condicionan y enmarcan la práctica del poder en la sociedad en general imponiendo la dominación. El poder es relacional, la dominación es institucional[4].
}

Castells entende que embora o poder esteja distribuído por todo âmbito social, o Estado, numa perspectiva histórica, é um artifício preponderante para pôr em funcionamento os mecanismos do poder. Entretanto, sabe-se que existe uma dependência entre o Estado e outras fontes de poder, o que insere a teoria de Castells nas redes globais sustentadas pelo acesso informacional. Daqui depreende-se a capacidade do Capital como sujeito autômato de emitir padrões de consentimento na produção discursiva que possibilitem a ingerência do social no aparato tecnológico, bem como, para o fechamento das instâncias decisórias. O que se quer ressaltar é a relação fetichista, ou seja, de distanciamento, do humano com suas possibilidades comunicativas por meio de redes jurídico-políticas voltadas para a administração tecnocorporativa da cidade.

Levando em consideração o acúmulo de informação e a possível assimilação destas como respostas aos desafios da cidadania, registra-se um movimento discursivo para o fechamento das alternativas tecnológicas marcado nas interações publico-privadas. Neste sentido, vale destacar o estudo de Francesco Maniglio sobre o processo de governar a União Europeia levado a cabo por diversos atores sociais que empregam o tecno-corporativismo para direcionar os contextos sociais relativos à cidadania.

Em seu trabalho, o pesquisador do Centro Internacional de Estudios Superiores de Comunicación para América Latina (CIESPAL), Francesco Maniglio informa acerca da relação dialética de redução/ampliação das possibilidades da cidadania europeia por meio do discurso 
tecnopolítico produzido na década de 2000-2010. Com o objetivo de analisar a convergência ideológica da governança europeia foram escolhidos quatro relatórios que marcam os planos decenais de ajuste estruturais para o desenvolvimento para a Economia do Conhecimento na Europa. Os quatros relatórios marcam a relação público-privada: (a) em 2000/2001 com o texto Conclusiones de la Presidencia: Consejo Europeo de Lisboa: 23 y 24 de marzo de 2000, pelo Conselho Europeu, e Actions for Competitiveness Through the Knowledge Economy in Europe: Message from the European Round Table of Industrialists to the Stockholm European Council, March 2001, autoria do grupo de pressão política das 50 principais empresas multinacionais da Europa; (b) em 2010, o texto EUROPA 2020. Una Estrategia para un crecimiento inteligente, sostenible e integrador da Comissão das Comunidades Europeias, no lado privado, novamente, o European Round Table of Industrialists com o texto ERT's Vision for a competitive Europe in 2025. Após proceder análise utilizando o software NVIVO 10 QSR International, a frequência de palavras reflete a orientação normativa produzida pelo discurso. O resultado da pesquisa demonstra o exercício estratégico-discursivo da relação sociedade/conhecimento/informação/economia nos moldes de uma expansão da cultura empresarial que possibilitaria uma melhor integração social e qualificação, logo, oportunidades de emprego e inovações sustentáveis (MANIGLIO, 2015).

As condições de reprodução social desempenhadas na Europa por meio da semântica do crescimento e do desenvolvimento constroem um dever ser implícito das relações sociais, ou seja, aprisionam as alternativas do futuro nos contextos técnico-estratégicos. O estado de coisas sem precedentes anunciado pela União Europeia na semântica da crise (MANIGLIO, 2015), só será superado - segundo o ideário tecno-corporativo - por meio de uma economia baseada no conhecimento, com maior competitividade e dinâmicas de alcance mundial. O que se pode concluir é que o início do século XXI é marcado pela constante fragilização do sentido intelectual da ideologia, isto é, da abertura para as disputas entre ideias. No contexto da administração dos antagonismos sociais revela-se a redução dos problemas ao nível técnico, uma desintelectualização que pode ser expressa na chave da ideologia sem ideologia, como conclui Maniglio.

A nova etapa do desenvolvimento hegemônico consiste na convergência entre diversos poderes, alianças entre atores sociais, agentes e instituições atravessadas por relações econômicas e tecnopolíticas. No nível formal, o desenvolvimento de políticas públicas em matéria de tecnologias, por exemplo, constitui uma proteção da sociedade da informação por meio da decomposição do Estado de bem-estar social e a projeção de novos imperativos (pós- 
)industriais. Resultando na geração de consensos público-privados que incorporam a tecnologia e o domínio das vias decisórias aos megagrupos financeiros e multimídias transnacionais (MANIGLIO, 2016).

No nível informal é possível observar que as relações entre os Estados-nação e as corporações estão intimamente ligadas por conveniências que operam para o fechamento das potencialidades da tecnologia em favor da manutenção de um status quo global. O caso do vazamento de dados do Wikileaks e o consequente controle sistêmico hegemônico acionado pelos EUA juntamente com grandes corporações financeiras como Paypal, Visa, MasterCard, é mais um exemplo de como a tecnopolítica reduz os espaços de autonomia do Direito. Neste sentido, um desenvolvimento apropriado da cibercultura - conquista de novas oportunidades emancipatórias para a cidadania - parece ainda estar bloqueado pela hegemonia político-cultural (ACOSTA JUNIOR, 2017).

\section{CONCLUSÃO}

O desenvolvimento tecnológico implementado na gestão das cidades, levando-as a receberem a denominação de cidades-inteligentes, compreende um movimento histórico-social. Neste sentido, o espaço urbano é influenciado pela onda "smart", mecanismos tecnológicos que utilizam-se da produção, armazenamento e organização da informação para a produção do espaço. Diante destas mudanças de caráter político-econômico a cidadania se vê reduzida de suas potencialidades, transformando cidadãos em consumidores-usuários. A forma mercadoria, então, elabora as condições de sociabilidade, algoritmizando o cotidiano, invadindo e colonizando as possibilidades de um planejamento urbano minimamente igualitário.

A cidadania reduzida a produção de dados para as elites controladoras dos fluxos informacionais garante a manutenção da cidade-empresa, em outras palavras, a exploração da cidade para a acumulação. Seja por dados ou monetariamente, a sociedade informacional caracteriza-se exatamente por esta capacidade de manutenção e transformação dos fluxos informacionais pelas elites. Com efeito, há uma reapropriação das redes por parte de uma forma de organização social tecno-política, destacando-se o tecno-corporativismo como o imbricamento discursivo público-privado que estabiliza os dominantes como tais.

O tecno-corporativismo emergente no século XXI constitui a artimanha de fetichização do direito à cidade. A sociedade informacional apresenta uma interessante contradição em relação a sua capacidade fundamental: a ampliação das tecnologias da 
informação e comunicação (TICs) não promoveram a ampliação da cidadania, e sim, seu inverso, ressaltou a incapacidade política, promovendo uma onda mercantilização na relação público-privada.

A continuidade tecno-corporativa insiste atravessando-se na relação sociedade/conhecimento/informação/economia, a superação da crise de suas contradições é novamente tapeada pela cultura empresarial, entregando - novamente - a legitimidade às corporações. A cidade como espaço habitado pelo humano transforma-se na via de rentabilização das corporações, o público convertido em mercadoria, a cidadania reduzida ao consumismo tecnocrático. Em suma, ao caráter de dúplice revolução do direito à cidade, tanto do cotidiano quanto da gestão, esboçam a necessidade de que a insurgência alcance as fissuras da tecnopolítica e ponha abaixo a administração fantasmagórica das corporações.

Tal qual Lefebvre que compreendia a revolução urbana com duas faces, uma da vida cotidiana e outra da gestão, na sociedade informacional conseguimos identificar a mesma necessidade - apesar da vida cotidiana transformada, ela incorre também em alienação e irracionalismo, de outro lado, do ponto de vista da gestão e das instituições políticas são necessárias formas que contemplem a participação em igualdade e coletiva - todavia, agora, tecnopolítica.

\section{REFERÊNCIAS}

ACOSTA JR. Jorge Alberto de Macedo. O paradoxo dos direitos humanos: cibercultura, wikileaks e o controle sistêmico-hegemônico. Revista Conversas \& Controvérsias, Porto Alegre, v. 4, n. 2, p. 42-61, ago.-dez. 2017.

ANJOS, Leonardo Fernandes dos. Por que "novos" direitos urbanos?. In: ANJOS, Leonardo Fernandes dos. Novos Direitos Urbanos - necessidades humanas que nascem das cidades. Lisboa: Theya Editora, 2017.

BONFIGLI, Fiammetta; KNEBEL, Norberto Milton Paiva. O Direito à Cidade enquanto prática jurídica no neoliberalismo. In: XXVI Congresso Nacional do Conpedi, 2017. São Luís - MA. Anais do GT Direito Urbanístico, Cidade e Alteridade. Florianópolis, 2017. Disponível em: https://www.conpedi.org.br/publicacoes/27ixgmd9/m4wq16h3.

CARLOS, Ana Fani Alessandri. A privação do urbano e o "direito à cidade" em Henri Lefebvre. In: CARLOS, Ana Fani Alessandri; ALVES, Glória; PADUA, Rafael Faleiros de. Justiça espacial e direito à cidade. São Paulo: Editora Contexto, 2017.

CASTELLS, Manuel. A sociedade em Rede. V. 1. 8. Ed. rev. Ampl. Tradução: Roneide Venancio Majer. São Paulo: Paz e Terra, 2005. 
CHENG, Bin et al. Building a big data platform for smart cities: Experience and lessons from santander. In: Big Data (BigData Congress), 2015 IEEE International Congress on. IEEE, 2015. p. 592-599. Disponível em: <https://ieeexplore.ieee.org/abstract/document/7207275/> . Acesso em: 30/08/2018.

DA SILVA, Paulo Celso. Smartcities: Modelo de comunicação Global? Uma abordagem da geografia da Comunicação. Em: Anais do XXXIX Congresso Brasileiro de Ciências da Comunicação. São Paulo, 2016. Disponível em: http://www.geografias.net.br/papers/2016/R11-1470-1.pdf. Acesso em: 30/08/2018.

KITCHIN, Rob. Big Data, new epistemologies and paradigm shifts. Big Data \& Society, v. 1, n. 1, 2014.

KITCHIN, Rob. Data-driven, networked urbanism. GeoJournal, 2015. Disponível em: < https://papers.ssrn.com/sol3/papers.cfm?abstract_id=2641802>. Acesso em: 31/08/2018.

LEAL, Suely. A utopia urbana da cidade do futuro: solidária e sustentável?. In: $8^{\circ}$ Congreso Internacional Ciudad y Territorio Virtual, Río de Janeiro, 10, 11 y 12 Octubre 2012. Centre de Política de Sòl i Valoracions, 2012. Disponível em: < https://upcommons.upc.edu/handle/2099/13334>. Acesso em: 31/08/2018

LEMOS, André. Cidade e mobilidade. Telefones celulares, funções pós-massivas e territórios informacionais. Matrizes, v. 1, n. 1, 2007.

LEMOS, André. Cidade-ciborgue: a cidade na cibercultura. Galáxia. Revista do Programa de Pós-Graduação em Comunicação e Semiótica. ISSN 1982-2553, n. 8, 2004.

MACHADO, Caio CV. Cidade dos Algoritmos: a Ética da Informação nas Cidades Inteligentes. 2018. Disponível em: <https://itsrio.org/wpcontent/uploads/2018/03/caio_machado_etica.pdf>. Acesso em 31/08/2017.

MANIGLIO, Francesco. Dirigir sin gobernar en la sociedad del conocimiento. El despotismo ilustrado en el discurso del techno-corporativism europeo. Discurso \& Sociedad, v. 9, n. 3, 2015.

MANIGLIO, Francesco. El gobierno del general intellect: la explotación de los conocimientos y la miseria de la humanidad. Quito: Ediciones CIESPAL, 2016.

MARICATO, Ermínia. É a questão urbana, estúpido!:“In”: HARVEY, D; MARICATO, E; et al. Cidades rebeldes. São Paulo: Boitempo, 2013.

NEVES, José Pinheiro. Das cidades inteligentes às metatopias urbanas. Revista de Comunicação e Linguagens, n. 48, 2018.

PIRES, Hindenburgo Francisco. Inovação tecnológica e desenvolvimento da Cibercidade: O advento da Cibercidade. In: Anais do Simpósio Internacional Cybercity, 2003. Disponível em: <http://www.cibergeo.org/artigos/CYBERCITY2003.pdf>. Acesso em: 21/08/2018 
SÁNCHEZ, Fernanda. A reinvenção das cidades para um mercado mundial. Argos: Editora Universitária, 2003.

SANTOS, Milton. Por uma outra globalização. Rio de janeiro: Record, 2000.

SANTOS, Milton. A natureza do espaço: técnica e tempo, razão e emoção. 4. ed. 2. Reimpr. São Paulo: Edusp, 2006.

TAVOLARI, Bianca. Direito à cidade: uma trajetória conceitual. Novos Estudos, n. 104, p. 92, 2016.

VAINER, Carlos B. Utopias urbanas e o desafio democrático. Revista Paranaense de Desenvolvimento-RPD, n. 105, p. 25-31, 2011.

VAINER, Carlos. Os liberais também fazem planejamento urbano? glosas ao. Plano Estratégico da Cidade do Río de Janeiro"“, en Arantes, O., Vainer, C. y Maricato, E.(comp.) A cidade do pensamiento único: desmachando consensos, Vozes, Petrópolis, 2000a.

VAINER, Carlos. Pátria, empresa e mercadoria: notas sobre a estratégia discursiva do Planejamento Estratégico Urbano. A cidade do pensamento único: desmanchando consensos, v. 3, p. 75-103, 2000 b.

WEISS, Marcos Cesar; BERNARDES, Roberto Carlos; CONSONI, Flavia Luciane. Cidades inteligentes como nova prática para o gerenciamento dos serviços e infraestruturas urbanos: a experiência da cidade de Porto Alegre. Revista Brasileira de Gestão Urbana, v. 7, n. 3, p. 310$324,2015$. 